ставляет собой композиты. Среди рассмотренных примеров неологизмов заимствования были замечены из английского и арабского языков, в то время как давние заимствования из латыни приобретают новые значения (Neubedeutungen).

Указанные особенности требуют поиска адекватных способов перевода, начиная от транслитерации и заканчивая описательно-разъяснительным комментарием. Всякий раз переводчику необходимо придерживаться переводческих норм, а также принимать во внимание особенности языка перевода.

1. Römer Ch. Der deutsche Wortschatz. Tübingen : Narr, 2019. 234 S.

2. Емельянова О. Н. Неологизмы // Энциклопедический словарь-справочник. Выразительные средства русского языка и речевые ошибки и недочеты / под ред. А. П. Сковородникова. М. : Флинта, 2005. С. 183-184.

3. Innerwinkler S. Neologismen. Heidelberg: Universitätsverlag Winter, 2015. 72 S.

4. Neologismenwörterbuch // OWID. URL: https://www.owid. de/docs/neo/start.jsp (дата обращения: 09.03.2020).

5. Konzeption Neologismenwörterbuch // OWID. URL: https://www.owid.de/wb/neo/konzept/Konzept02.html (дата обращения: 09.03.2020).

УДК 811

Науч. спец.: 10.02.01

DOI: $10.36809 / 2309-9380-2020-26-63-67$

\section{ОСОБЕННОСТИ ПРЕДСТАВЛЕНИЯ ЦЕННОСТНО-ОЦЕНОЧНЫХ ЗНАЧЕНИЙ В РАЗВЛЕКАТЕЛЬНОМ ФОРМАТЕ ТОК-ШОУ}

В статье рассматриваются особенности представления аксиологических значений в ток-шоу «Андрей Малахов. Прямой эфир»: жесткая закрепленность оценок того или иного типа за разными участниками передачи, сбалансированное чередование негативных и позитивных оценочных смыслов, амбивалентность итоговых оценок, эмоционально-экспрессивный характер оценочных высказываний. Показано, что данные особенности обусловлены специфической чертой формата ток-шоу — жестким сценарием, который направлен на удержание внимания зрителей, поддержание высокого градуса конфрликта, имитацию естественной коммуникации.

Ключевые слова: ценности, оценки, ток-шоу, «Андрей Малахов. Прямой эфир», сценарий, псевдокоммуникация, конфрликт.
6. Stichwörter in Sachgruppen // OWID. URL: https://www. owid.de/docs/neo/gruppen.jsp (дата обращения: 09.03.2020).

7. Duden online. URL: http://www.duden.de (дата обращения: 09.03.2020).

8. Буренкова С. В. Исследование динамики немецкого концепта Familie // Вестн. Ом. гос. пед. ун-та. Гуманитарные исследования. 2018. № 4 (21). С. 56-59.

9. Bundesverfassungsgericht für drittes Geschlecht im Geburtenregister // Zeit online. URL: http://www.zeit.de/gesellschaft/ zeitgeschehen/2017-11/bundesverfassungsgericht-fuer-drittesgeschlecht-im-geburtenregister (дата обращения: 09.03.2020).

10. Duden. Deutsches Universalwörterbuch. 4. Aufl. Mannheim, Leipzig, Wien, Zürich : Dudenverlag, 2001. 1892 S.

11. Offener Brief: Absage an "Gender-Wildwuchs" // KURIER. URL: https://kurier.at/politik/inland/offener-brief-deutliche-absage-ans-gendern/74.865.264 (дата обращения: 09.03.2020).

12. Карцев Д. «Обучающие» вместо «учителей», «избирающая персона» вместо «избирателя». В Ганновере внедряют гендерно-нейтральный язык - мы перевели на русский // Meduza : новости. URL: https://meduza.io/feature/2019/01/23/ obuchayuschiy-vmesto-uchitelya-izbirayuschaya-persona-vmestoizbiratelya-v-gannovere-vnedryayut-genderno-neytralnyy-yazykmy-pereveli-na-russkiy (дата обращения: 09.03.2020).

(C) Буренкова С. В., 2020

\title{
FEATURES OF PRESENTING VALUE-EVALUATIVE MEANINGS IN THE ENTERTAINMENT FORMAT OF TALK SHOWS
}

The article discusses the features of the presentation of axiological meanings in the talk show "Andrey Malakhov. Pryamoy Efir": tough fixation of evaluations of one or another type for different participants of the program, balanced alternation of negative and positive evaluative meanings, ambivalence of final evaluations, emotionally-expressive nature of evaluative statements. It is shown that these features are due to a specific feature of the talk show format - a tough script that is aimed at keeping the attention of the audience, maintaining a high degree of conflict, simulating natural communication.

Keywords: values, evaluations, talk show, "Andrey Malakhov. Pryamoy Efir", script, pseudo-communication, conflict.

Ценностно-оценочная квалификация явлений, событий, людей и их поступков сформирована в сознании каждого индивида под влиянием принятых социуме представлений о тех или иных характеристиках окружающей действительности. Аксиологические представления объективируются в процессе социальной активности человека - субъекта и объекта оценки.

Философр Г. П. Хорина считает, что Россия живет в аксиологической неопределенности, которую демонстрирует современная социальная практика. С одной стороны, 
сохраняются ценности старые, традиционные; с другой в сознание людей проникают новые, как правило либеральные, многие из которых при этом не воспринимаются большей частью населения [1]. По мнению Е. В. Поликарповой, массмедиа уже давно вошли в психосоциальную среду обитания человечества, претендуют на роль мощного фактора формирования мировоззрения личности и ценностной ориентации общества, лидируют в области идеологического воздействия, транслируют культурные достижения и активно влияют на формирование культурных ценностей. Исследователь акцентирует внимание на том, что эти процессы зачастую остаются бесконтрольными и малоизученными [2].

Эксплуатация разного рода ценностей и оценок, в том числе морально-этических, характерна для развлекательного медиадискурса. Данный сегмент СМИ - один из инструментов влияния на мнение аудитории. Особенно ярко это влияние наблюдается в жанре ток-шоу, что делает актуальным обращение к нему с целью исследования особенностей выражения ценностных значений.

Исследование, результаты которого представлены в статье, выполнено в рамках дискурсивной парадигмы, позволяющей, в частности, представить особенности жанра сквозь призму его ценностно-оценочных ориентаций и, напротив, увидеть обусловленность средств и способов выражения оценочных значений канонами жанра. Отметим, что теория оценки занимает важное место в отечественном языкознании (сошлемся на труды Н. Д. Арутюновой [3], Е. М. Вольф [4] и др.); исследование телевизионного развлекательного дискурса через со- и противопоставление его жанров - одно из динамично развивающихся лингвистических направлений.

Одно из самых популярных массовых ток-шоу на российском телевидении - «Андрей Малахов. Прямой эфир». Передачи транслируются каждый будний вечер по телеканалу «Россия-1» с 2017 г. В передаче присутствует несколько героев, конфрликт между которыми обсуждается. Субъекты оценки - эксперты в студии; приглашенные гости, знакомые с героями, которых они обвиняют или защищают; зрительный зал; ведущий (Андрей Малахов), модеририующий обсуждение. Структура субъектов оценки в точности соответствуют выделенным П. В. Гуленко и Ю. И. Долговой элементам ток-шоу: 1) харизматичный ведущий; 2) приглашенные собеседники (эксперты); 3) публика в студии; 4) зрители у экранов телевизоров [5]. Стоит только сделать оговорку, что оценка зрителей остается «за кадром».

В результате обзора тем выпусков и аннотаций к ним на официальной странице ток-шоу за первое полугодие 2018 г. (107 выпусков) нами выявлена типичная сюжетная схема - «X бросил Y-а» (15\% от общего числа выпусков). Материалом для статьи стала передача, вышедшая в эфир 12 января 2018 г. под названием «Звезда в шоке! Сергей Зверев женился!» [6]. В ней представлен один из вариантов указанного сюжета, который в речи модератора формулируется как вопрос: Почему звездный отец отрекся от единственного сына и вычеркнул из своей жизни? Обращает на себя внимание прецедентный текст звезда в шоке, отсылающий массового зрителя к личности стилиста Сергея Зверева, ставшего заочным героем передачи (так как в студии его не было). Второй герой и участник конфрликта - его приемный сын, Сергей Зверев-младший. Позицию сына разделила его новая жена Юлия - третий герой выпуска. Суть конфликта между героями заключалась в том, что Сергей Зверев-младший женился без ведома отца во второй раз, на бывшей коллеге. На протяжении 55 минут экранного времени зритель следит за обсуждением ситуации. В процессе обмена мнениями участники дают оценку героям и их поступкам.

Фактором, влияющим на организацию в материале ценностно-оценочных смыслов, является жесткий сценарий. Г. В. Кузнецов, который одним из первых в России обратился к изучению ток-шоу, назвал сценарий этого формата «железным» [7]. Исследуемая передача не является исключением: она соответствует всем требованиям к подобным программам как композиционно (состоит из постоянных структурных элементов), так и содержательно.

Четко просматривается развитие сюжета. Во вступительной части Андрей Малахов вводит зрителей в курс повествования: На днях состоялась свадьба Сергея Зверева-младшего. Это уже второе бракосочетание 24-летнего парня. Оба торжества звездный отец Зверев-старший проигнорировал. Это своеобразная аннотация, которая повторяется на протяжении всей программы после рекламы. После приветственного слова зрителям демонстрируется видео, иллюстрирующее суть проблемы. Ведущий использует метод интервью: ведет диалог с героиней и с героем, затем переходит к экспертам, приглашает гостей, имеющих заранее известную позицию.

Следование строгому сценарию демонстрирует расnределение ролей.

Андрей Малахов как модератор обсуждения представляет нейтральную точку зрения. Зачастую его реплики имеют вопросительную форму: Малахов: А у вас тоже второй брак? - Юлия: Нет. У Сережи второй. - Малахов: У вас есть родители? - Юлия: Да, конечно. Вопросы инициируют обсуждение. Герои, Сергей Зверев-младший и его спутница, отстаивают свою позицию, которая заключается в том, что они зарабатывают на жизнь сами, любят друг друга, не хотят публичности и не против поддерживать отношения с отцом героя: Малахов: Юль, а вы как объясните, почему ваших родителей не было, Сергея не было? - Юлия: Ну, во-первых, мы просто хотели свадьбу для себя, вот. Вдвоем просто расписаться.

Эксперты выступают в качестве критиков, имеющих право на оценку: Эксперт (Дмитрий Сорока): ...nотом мы удивляемся, почему ребенок не приспособлен к жизни, и говорим, что он не может обеспечивать семью, не может зарабатьвать деньги; Эксперт (автор тренингов): Вы знаете, это ужасно. И самое ужасное в этой ситуации то, что они на самом деле могут быть счастливы...

Гости высказывают оценки, зависящие от того, «с чьей они стороны». Рустам Солнцев, друг молодой семьи, защищает этот брак: (о свадьбе) В этом была какая-то, знаете, доверительная атмосфрера. Мы втроем очень хорошо провели время. Я песню даже ребятам спел, они танцевали. Красавчики. Лера Тувина, знакомая Сергея Зверевастаршего, осуждает Зверева-младшего: ... Ты гулял, ты 
прогуливал, ты от военкомата прячешься, к папе постоянно приходят домой военные, приходят приставы, потому что куча кредитов он понабрал и ему дают, потому что у него отец - Сергей Зверев.

Последовательность реплик участников передачи (без ведущего и главных героев) четко отражает чередование противоположных позиций в структуре ток-шоу. Приведем в качестве примера начальный фрагмент передачи:

Гость, Рустам Солнцев, ЗА пару.

Эксперт, имя неизвестно, ПРОТИВ пары.

Эксперт, Дмитрий Сорока, психолог, ЗА пару.

Эксперт, Алексей Леденев, ПРОТИВ пары.

Гость, Лера Тувина, ПРОТИВ пары, ЗА отца.

Эксперт, Дмитрий Сорока, ПРОТИВ отца.

Гость, Сабина Матвеева, администратор отеля, ПРОТИВ пары.

Гость, Роман Смирнов, топ-стилист, ЗА пару.

Гость, Лера Тувина, ЗА отца.

Гость, Отар, ЗА пару.

Видео, Галина Кочеткова, ЗА сына.

Гость, Катя, подруга Сергея, ПРОТИВ пары, ЗА отца.

Гость, Рустам Солнцев, ЗА сына.

Подобное чередование обвинения и защиты, выдерживаемое на протяжении всей передачи, создает напряженность, придает разговору конфоликтную тональность. Наряду с выраженными оценками противоположного знака, сталкиваются имплицитные оценочные суждения:

Малахов: Скажи мне, а ты знала, что Сергей был женат... (в контексте скорее отрицательно-оценочная характеристика героя). - Юлия: Да, он не скрывал этого (положительная оценка, акцентируется честность молодого мужа). - Малахов: И как ты отнеслась вот? - Юлия: Спокойно. Просто там ничего такого не было настолько серьезного (отрицательная оценка прежних отношений). Эксперт: Юля, а как вы поняли, что у вас более серьезно, чем было тогда? Почему вы решили, что у вас более серьезно? (на поверхности оценочно-нейтральное высказывание, уточняющий вопрос). - Юлия: Во-первых, мы друд другу признаемся в любви. В первом браке этого не было. Bom (подкрепление точки зрения доводом, оформленным как рациональное суждение). - Эксперт: Это не показатель совсем (общий вывод эксперта - негативный).

Противостояние позиций обнаруживается не только в пределах диалога, но и в границах одной реплики: Малахов: Что движет гламурным папой? Желание защитить сына или банальная отцовская ревность?; Юлия Шестакова, подруга Сергея: Я хочу просто понять, она реально любит человека или она просто хотела пиара всем этим. Подобные конструкции поддерживают паритетность мнений, что пересекается со следующей особенностью аксиологического пространства ток-шоу.

Выверенный баланс точек зрения имеет результатом амбивалентность результирующих оценок. Передача как будто бы завершается репликой ведущего, наставлением-напутствием Сергею Звереву-младшему: Андрей Малахов советует ему наладить отношения с отцом и для этого измениться. Такой финал показал бы одностороннюю правоту Сергея Зверева-старшего, однако этого не случается.
Под занавес следует фраза героини о своем избраннике: Но он уже изменился! Героиня остается при своем мнении, а заявленные социальные проблемы (отцы и дети, причины конфликтов, гиперопека старших и инфантильность молодых и т. д.) остаются нерешенными.

Важно не выяснение истины, а эмоциональный фон обсуждения, конфликт, о котором уже говорилось в связи с композицией передачи. Как считают исследователи, развитие конфликта в ток-шоу отличается от этого процесса в естественной коммуникации. В. Е. Ершова отмечает, что он может зародиться (предконфоликтная ситуация) и сразу завершиться; может быстро последовать кульминация, после которой не наступит спад, и т. д. [8, с. 16-18].

В анализируемой передаче не зафиксированы агрессивные фрормы конфликта, в том числе переход от обсуждаемой проблемы к выяснению отношений между участниками. В то же время представляют интерес способы повышения «градуса эмоций» со стороны ведущего, эмоционально-оценочные смыслы, сопровождающие запрос информации в его репликах. Формулируя вопрос, ведущий прямо не выражает оценку, но она, тем не менее, присутствует: Малахов - Юлии: Даже если мы подумаем, что нет ребенка... А вот вы считаете, Сергею Звереву хотелось, чтобы его сын женился и в руках у невесты был букет искусственных цветов?; Малахов: Понятно. Сергей, а ты как друг детства... Тебе обидно, что тебя не позвали на свадьбу?

Поддерживая определенный уровень конфликтности, ведущий предлагает провокационные вопросы сразу после нейтральных или реплик в защиту героев: Юлия: Да, у меня все в первый раз. - Малахов: Все в первый раз. И сейчас мы увидим первый танец жениха и невесты. И, конечно, главный вопрос, который волнует всех: почему папу-то вы не позвали?; Малахов: Ну а ты почему не рассказываешь девушкам; вы знаете, кто мой папа? - Зверевмладший: Ну зачем? Ну это, как сказать, проверка, тест, может, такой. - Малахов: То есть, если Юля выдержала скромную свадьбу, если Юля живет вместе с тобой на съемной квартире, то это всего лишь тест-драйв?

Отмечается, что в последнее время глобальным коммуникативным намерением ведущего развлекательных ток-шоу становится дискредитация гостей студии. Такое поведение ведущего обусловлено необходимостью обострения проблемной ситуации и, как следствие, привлечения внимания зрителей. Нельзя сказать, что в анализируемой передаче дискредитация кого-либо из героев является доминирующей стратегией ведущего, но отдельные черты подобного речевого поведения присутствуют. В репликах Андрея Малахова о героях передачи встречаются весьма экспрессивные формы оценочных клише, отбираются синонимы с семантикой интенсивности: отрекся, вычеркнул из жизни, проигнорировал, избиваешь и т. д.: Малахов o Сергее Звереве-младшем: А скажи, пожалуйста, а ты не боишься, что, Юль, все-таки у Сережи была история c первым браком, которая тоже закончилась здесь, на ток-шоу, когда Маша призналась, что ты (обращается к Сергею) ее избиваешь; Малахов - о Юлии: Здесь Сергей Зверев-старший также переживает, что молодая девушка, он сказал, взяла фрамилию, как я понимаю, Зверева. 
Tеперь она Зверева, теперь она на экранах, и теперь она будет таскать его сына, как он когда-то вовлекал в свой бизнес; Малахов - о Сергее Звереве-старшем: А вот вопрос. Действительно, Алеш, как ты считаешь, что Сергей дал своему сыну во взрослую жизнь, кроме фамилии, красивых причесок и общеобразовательного уровня в школе?

«Железный» сценарий приводит к тому, что в передаче проявляются черты псевдокоммуникации, имитации диалога.

С одной стороны, дискуссия сходна с естественной. Вопервых, участники исходят из общих ценностей, которые к тому же проецируются на зрителя, сталкивавшегося с подобной проблемой. (Эта особенность ток-шоу отмечена исследователями [9, с. 117] и отражена в нашем материале: Эксперт (Дмитрий Сорока): ...к сожалению, это проблема не только звездных родителей, но и просто родителей.) Во-вторых, зачастую она ведется в формате «вопрос - ответ», что, казалось бы, иллюстрирует естественную коммуникацию: Роман Смирнов, топ-стилист: Откуда Вы знаете? - Лера Тувина: Я знаю, это все на моих глазах происходит.

Однако при более внимательном рассмотрении обнаруживаются признаки инсценированного дискурса.

Ослаблена когезия. Ответ может быть не связан с поставленным вопросом: Малахов: Какие отношения были у Сергея-младшего с папой? - Людмила Прокошина: Это было, когда мы были намного взрослее. В тот момент они вроде как не общались, или не так часто это было. Задаются вопросы, в том числе конкретному человеку, ответить на которые адресату не дают возможности: Юлия Шестакова: Юля, ты мне сказала, что вы расписались. У меня вопрос: зачем ты обманула меня?

Остаются невыясненными некоторые обстоятельства, что обязательно было бы сделано в естественном разговоре. Зрители так и не узнали, есть ли у Юлии ребенок, хотя эта тема поднимается на протяжении всей передачи и становится предметом споров: Малахов: Но Сергей знает, что есть ребенок, да? - Лера Тувина: Ну Сергею донесли, что есть ребенок, что он не слишком здоров... Эксперт (Наталья Морозова, семейный психотерапевт): Один раз вы сказали - нет ребенка, и тут что, секрет Полишинеля? Все-таки он есть или нет? - Зверев-младший: Был бы ребенок, я бы даже такого взял. Любого. Юлия: Детей нет. Это просто слухи. Активно, но безрезультатно обсуждается и другая информация фрактического характера: обеспечивает ли отец семью сына, общается ли сын с отцом.

Не поддается адекватной интерпретации смена эмоционально-оценочного посыла некоторых участников передачи: Юлия Шестакова, подруга Сергея: Андрей, я сюда пришла, чтобы, во-первых, поздравить Сережу с Юлей, потому что я искренне желаю им счастья, вот, я очень люблю Сережу и желаю, чтобы он был счастлив, потому что Сережа очень искренний, душевный человек... У меня просто есть несколько вопросов к Юле. Я хочу задать провокационны й вопрос. Я хочу просто понять, она реально любит человека или она просто хотела пиара всем этим.

О героях, сидящих в студии, говорят в третьем лице: Малахов: Четырнадцатилетие Сергея Зверева- младшего, он стесняется смотреть...; Юлия Шестакова: Она поменяла свою фамилию в соцсетях на Юлия Зверева еще в конце августа прошлого месяца; Эксперт (автор тренингов): Ну, это же нормально, что ей хочется замуж! И это хорошо; Катя Гусева: ...готов ли Сергей уже тянуть ее ребенка? (При этом сами молодожены наличие ребенка отрицают.) Ни один из присутствующих в студии героев передачи не возражает Андрею Малахову, «не замечая» провокационных вопросов. Сложно представить, чтобы это происходило в естественной коммуникации.

Псевдокоммуникация создает некую параллельную реальность, в которой не имеет значения выяснение истины и разрешение споров.

Подведем итоги. Б. Б. Сибиданов, говоря о ток-шоу, приходит к заключению, что происшествия и случаи, рассматриваемые в передачах этого формата, выходят далеко за рамки обычных человеческих взаимоотношений. Тем самым создатели вызывают зрительское любопытство. По мнению ученого, это трэш-продукт, который «паразитирует на проблемном содержании, претендующем на значимость и стремящемся к какому-либо серьезному изменению общественного или даже государственного уклада» $[10$, c. 5]. Проведенный анализ подтверждает этот тезис. Рассмотренная передача «Звезда в шоке! Сергей Зверев женился!» претендует на трансляцию социальной проблемы, имеющей аксиологический статус (причины конфликтов между родителями и взрослыми детьми, инфантильность молодых людей и др.). На протяжении передачи говорится об общечеловеческих ценностях, но выводы по конкретной ситуации не сделаны. Проблемы, заявленные в начале передачи, не решаются.

Жесткий сценарий передачи обусловил продуманное распределение оценочных суждений между разными участниками, сбалансированное чередование смыслов, противоположных по знаку оценки, двойственность и неопределенность итоговых суждений. Эмоционально-экспрессивный характер оценочных высказываний, провокационные вопросы и замечания обеспечили необходимый в ток-шоу уровень конфликтности. Средой функционирования ценностно-оценочных значений явилась псевдокоммуникация, имитирующая естественный разговор и отражающая условную реальность. Отсюда следует, что поиск истины, конструктивное обсуждение, выявление подлинных ценностей - всё это не входит в задачи передачи. Она несет развлекательную функцию, воздействуя на эмоции и инстинкты зрителя.

1. Хорина Г. П. Ценности русской культуры в условиях цивилизационного кризиса // Информационный гуманитарный портал «Знание. Понимание. Умение». 2016. № 6. C. 16-26. URL: http://zpu-journal.ru/e-zpu/2016/6/Khorina Values-of-Russian-Culture (дата обращения: 20.12.2019).

2. Поликарпова Е. В. Аксиологические функции массмедиа в современном обществе // Библиотека «Гумер». URL: http://www.gumer.info/bibliotec_Buks/Polikarp/01.php (дата обращения: 20.12.2019). 
3. Арутюнова Н. Д. Язык и мир человека. М. : Языки русской культуры, 1999. 896 с.

4. Вольф Е. М. Функциональная семантика оценки. М. : Наука, 1985. 228 C.

5. Гуленко П. В., Долгова Ю. И. Проблемы классификации современных телепередач: сущностные характеристики формата «ток-шоу» // Вестн. Рос. ун-та дружбы народов. Сер. Литературоведение, журналистика. 2016. № 3. С. 102-110.

6. Звезда в шоке! Сергей Зверев женился // Прямой эфир : [сайт]. URL: https://pryamoj-efir.ru/pryamoj-efir-12-012018-zvezda-v-shoke-sergej-zverev-zhenilsya (дата обращения: 20.12.2019).

УДК 811

Науч. спец.: 10.02.01

DOI: 10.36809/2309-9380-2020-26-67-71

\section{РУССКОЕ КОММУНИКАТИВНОЕ ПОВЕДЕНИЕ В УСЛОВИЯХ ВИРТУАЛЬНОГО ОБЩЕНИЯ}

В статье на примере анализа виртуальной коммуникации в жанре комментария рассматриваются особенности проявления русского коммуникативного сознания личности в условиях виртуального общения. В качестве материала используются комментарии пользователей социальной сети «Инстаграм». Как наиболее релевантные для общения в виртуальной среде выделены такие категории (концепты), как вежливость, эмоциональность, юмор, оценочность, давление, конфрликт, «сохранение лица». В ходе исследования выявлены некоторые отличительные особенности коммуникативного поведения и коммуникации в целом в условиях виртуальной среды.

Ключевые слова: виртуальная коммуникация, коммуникативное сознание, коммуникативная категория, комментарий, конфликт.
7. Кузнецов Г. В. Так работают журналисты ТВ. М. : Изд-во Моск. ун-та, 2000. 224 с.

8. Ершова В. Е. Стилистические особенности конфрликтных текстов ток-шоу // Вестн. Том. гос. ун-та. 2012. № 365. С. 15-18.

9. Акинфеев С. Н. Развлекательное телевидение: определение, классификация, жанры // Вестн. Моск. ун-та. Сер. 10. Журналистика. 2008. № 6. С. 110-124.

10. Сибиданов Б. Б. Две формы отрицания в телевизионном трэш-дискурсе // Учен. зап. Новгород. гос. ун-та. 2019. № 1 (19). С. 1-7.

(C) Васильева Д. С., 2020

А. Гриценко

A. Gritsenko

\section{RUSSIAN COMMUNICATIVE BEHAVIOUR IN CONDITIONS OF VIRTUAL COMMUNICATION}

This article uses the example of virtual communication analysis in the commentary genre to examine the features of the Russian communicative consciousness in virtual and real communication. Comments from users of Instagram are used as a material. Communicative consciousness can be described in terms of different communicative categories. In this paper, such categories (concepts) as politeness, emotionality, humour, evaluation, pressure, conflict, "face-saving" are identified as the most relevant for communication in a virtual environment. The study revealed some distinctive features of communicative behavior and communication in general in a virtual communication environment.

Keywords: virtual communication, communicative consciousness, communicative category, commentary, conflict.
В настоящее время межличностное общение находится в центре исследований разных дисциплин. Природу речевой коммуникации на протяжении долгих лет исследуют с точки зрения психологии, лингвистики, нейролингвистики, социологии, естественных наук. Для языкознания, помимо прочих, актуальны понятия коммуникативного поведения и коммуникативного сознания.

Коммуниканты выбирают то или иное коммуникативное поведение, обусловленное особенностями воспитания человека, местом его рождения и обучения, его принадлежностью к той или иной социальной группе, национальности, личными особенностями (см. об этом: [1]). Коммуникативное поведение стереотипно и в то же время индивидуально, так как стандартные ситуации общения вызывают типичное речевое поведение, с одной стороны, и индивидуальные речевые проявления конкретной личности - с другой. Таким образом, каждой языковой личности свойственно личностное коммуникативное поведение, понимаемое как комплекс норм и традиций общения отдельной личнос- ти, которая принадлежит определенному времени, стране, социальной группе, семье и обладает коммуникативным сознанием. Последнее являет собой «устойчивую совокупность мыслительных категорий, отражающих нормы, правила и традиции, обеспечивающие коммуникативное поведение (нации, группы, личности)» [2, с. 51].

С развитием высоких технологий модисрицируются способы и формы межличностного взаимодействия. Коммуникация стала возможной не только в реальной среде, но и в виртуальной. Данный фракт не может не повлиять на характеристики как коммуникации в целом, так и ее отдельных компонентов. Как самостоятельная сфера вербального взаимодействия, особое коммуникативное пространство, которое одновременно и определяет цели, способ и среду общения, и определяется ими [3, с. 7], рассматривается виртуальное общение. В связи с тем что одним из свойств виртуального события является измененность (статуса личности, статуса свободы, статуса воли) [4, с. 153], при взаимодействии с виртуальными личностями сознание переходит на качественно новую 